\title{
Cell Balancing Method in Flyback Converter without Cell Selection Switch of Multi-Winding Transformer
}

\begin{abstract}
Jin-Woong Kim* and Jung-Ik Ha ${ }^{\dagger}$
Abstract - This paper presents a cell balancing method for a single switch flyback converter with a multi-winding transformer. The conventional method using a flyback converter with a multi-winding transformer is simple and easy to control, but the voltage of each secondary winding coil might be non-uniform because of the unequal effective turn-ratio. In particular, it is difficult to control the nonuniform effect using turn-ratios because secondary coil has a limited number of turns. The nonuniform secondary voltages disturb the cell balancing procedure and induce an unbalance in cell voltages. Individual cell control by adding a switch for each cell can reduce the undesirable effect. However, the circuit becomes bulky, resulting in additional loss. The proposed method here uses the conventional flyback converter with an adjustment made to the output filters of the cells, instead of the additional switch. The magnitude of voltage applied to a particular cell can be reduced or increased according to the adjusted filter and the selected switching frequency. An analysis of the conventional converter configuration and the filter design method reveals the possibility of adequate cell balancing control without any additional switch on the secondary side.
\end{abstract}

Keywords: Battery management system, Cell balancing, Flyback converter, Multi-winding transformer

\section{Introduction}

Recently, lithium-ion battery and super-capacitors of high output voltage with series connections are being used in many high power applications such as hybrid or pure electric vehicles and energy storage systems [1-4]. They have several pros and cons compared with the conventional lead-acid battery. The volume and weight of a lithium-ion battery pack can be reduced because of its high energy density. However, since batteries store energy in a chemical form through an electrochemical reaction, the permitted current can be quite limited. Super capacitors store energy in an electrical form and thus have more flexible current limits. But more cells are required for a high output voltage because of the low voltage limit, which of 2.0-2.7V [5].

The cell voltage of the battery and super-capacitor have their upper and lower limits. If the cell voltage exceeds its limit, there could lead to potential safety and lifetime issues. These can be prevented through the implementation of a battery management system (BMS). The BMS monitors the voltage of each cell and protects the battery cells from over-charging and discharging [6-8]. Another function of the BMS is the protection from unbalanced cell voltages. As each cell has unequal properties such as capacity, ESR and self-discharge current, cell voltages can become unbalanced as the charging and discharging sequences are repeated in the series connection

$\dagger$ Corresponding Author: Dept. of Electrical and Computer Engineering, Seoul National University, Korea. (jungikha@snu.ac.kr)

* Dept. of Electrical and Computer Engineering, Seoul National University, Korea. (tndud37@snu.ac.kr)

Received: January 16, 2015; Accepted: October 14, 2015 configuration [9-10]. Even though the BMS prevents safety problems associated with the unbalanced state, the available capacity of the battery or super-capacitor pack may be dramatically reduced, as the BMS applies upper and lower limits to the highest and lowest voltage cells [11-15]. Fig. 1 shows the cell state of charge (SoC) according to battery $\mathrm{SoC}$ for the cases of battery packs with balanced and unbalanced cells. As shown in Fig. 1(a), almost 90\% of energy can be used in charging and discharging states. In contrast, Fig. 1(b) shows that some cells may not be fully used because of cell 1 being in the discharging state and other cells cannot be fully charged because of cell 3 being in the charging state. Therefore, cell voltage balancing is important for maximizing the battery capacity [16-18].

Recently, various cell balancing methods have been researched, and they can be typically categorized into two types: passive method and active method. The main idea of the passive method is to dissipate the energy of the highest voltage cell for balancing. By consuming energy stored in the cell that resides at a higher voltage than the average cell voltage through a resistor, the voltage difference is reduced [19]. This method is easy to implement and control but dissipates the energy as heat, thereby resulting in low efficiency [20-22]. In contrast, the active method transfers energy from the highest voltage cell or the pack to other cells. An additional balancing circuits of both methods have a loss. So the energy of a battery pack will be dissipated when the balancing sequence is repeated. However, as the energy is not dissipated but transferred in the active method, it results in higher efficiency. The charge shuttling method is one of the typical active 


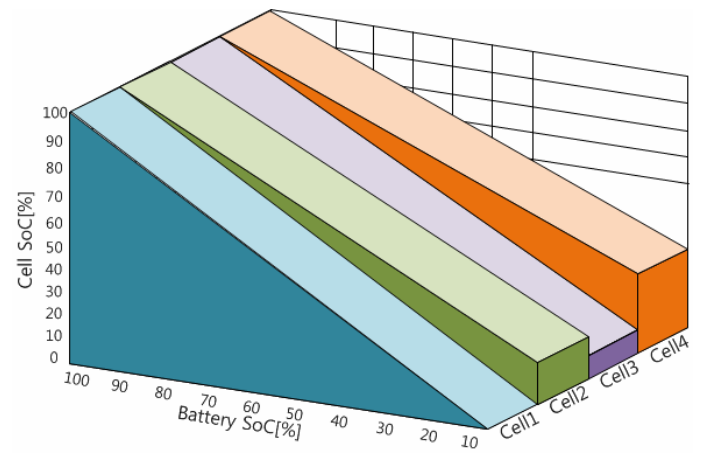

(a)

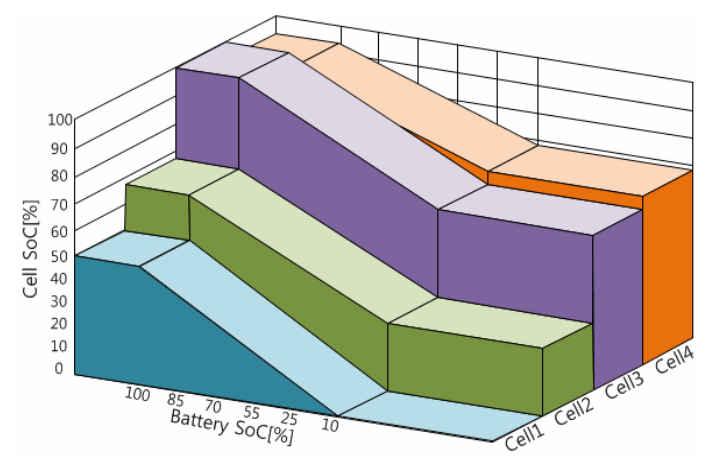

(b)

Fig. 1. Cell SoC according to Battery SoC: (a) Balanced cell voltages at $100 \%$ Battery SoC and (b) Unbalanced cell voltages at $100 \%$ Battery SoC.

methods. At a certain switching frequency, the energy of the highest voltage cell is transferred to other cells through a capacitor as the medium [23]. Therefore, the cell balancing can be done automatically without the need for any cell voltage monitoring and control algorithm [24]. However, it takes a long time to balance two cells in far stacking positions because the energy should be transferred through every cell and capacitor between the cells. To reduce the balancing time, several methods such as the chain structure method or the modularized system method have been proposed. The former method connects the first cell to the last cell with an additional capacitor and the latter method groups several cells to reduce the balancing time. Although these methods are practically applicable, the balancing speed is lower than that of other cell balancing methods.

Using the multi-winding flyback converter is one of the simple and easy methods of active cell balancing [25, 26]. The primary side of the converter is connected to the whole string of cells, and the secondary side is connected to each cell as shown in Fig. 2(a). During the turn-on state of the switch, the energy is released from whole module, and during the turn-off state, energy is transferred to each cell according to the difference between the average cell voltage and individual cell voltage. In effect, the cell balancing can be performed at the fixed switching frequency without any additional consideration [27].

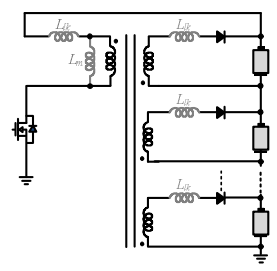

(a)

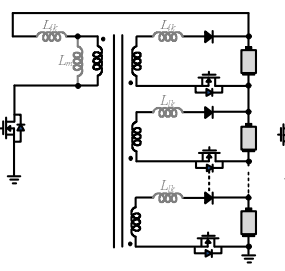

(b)

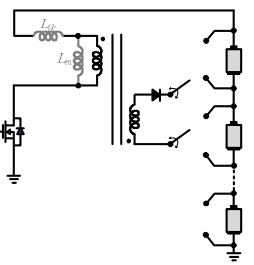

(c)
Fig. 2. Conventional cell balancing methods with flyback converter: (a) Multi-winding transformer; (b) Multiwinding transformer with cell switches; (c) Single winding transformer.

However, the multi-winding transformer on a single core causes problems such as non-uniformity in the effective turn-ratios, which in turn disturbs the cell balancing procedure. To avoid this effect, a switch is added to each cell as shown in Fig. 2(b). This approach reduces the multiwinding effect caused by an individual cell balancing. However, the system becomes highly complex because of the additional switch and the control for each cell [28]. Fig. 2(c) exhibits another method to avoid the multi-winding effect. This method uses a single winding on the secondary side and adds two switches for each cell to select the cell requiring balancing [29]. However, similar to the above method, the circuit and the control become complex because of the additional switch.

In this paper, a cell balancing control method using a single switch flyback converter with a multi-winding transformer and adjusted output filters is proposed. The whole circuit diagram and control method are simplified because of the filter adjustments without any additional switches. Moreover, the filters are designed based on the frequency characteristic for cell selection control. Due to the adjusted filters and the selected switching frequency, non-uniformity in the turn-ratio of the secondary windings can be eliminated.

This paper consists of the following sections: In Section II, the proposed topology and operation of the balancing process are introduced. Then, two types of filters are defined according to the non-uniform turn-ratios and their properties are explained. In addition, a general filter, which is a combination of two types of filters, is also introduced. In Section III, the control method for the proposed topology and the design of the proposed filters are described. Simulation results with super capacitors and experimental results with Lithium-Polymer (Li-Po) batteries are presented in Section IV.

\section{Proposed Topology}

The proposed topology uses a flyback converter with a multi-winding transformer for simplicity. Simultaneously, non-uniform turn-ratios in multi-winding transformer are compensated, and the cell selective control can be done 
with the adjusted filter and switching frequency. There are two types of non-uniform turn-ratios in a multi-winding transformer. The first type is the higher effective turnratio and the other type is the lower effective turn-ratio. The former makes secondary voltage higher and the latter makes the voltage lower at the relevant winding. As a result, these uneven secondary voltages disturb the balancing procedure. Therefore, to enhance the performance of cell balancing, two types of filters for each case and a combinational general filter for any case are proposed.

\subsection{Band amplification CL filter}

Fig. 3(a) shows a circuit diagram of the $k^{\text {th }}$ filter, which is used in the lower secondary voltage case. A transfer

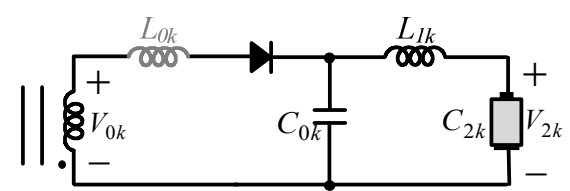

(a)

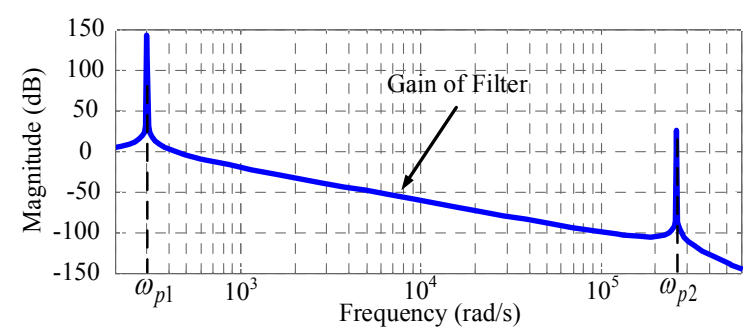

(b)

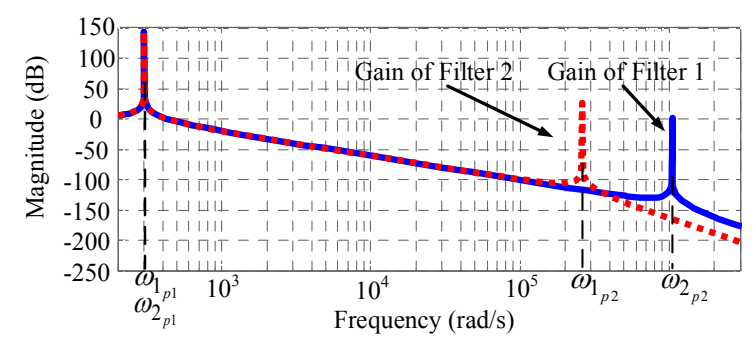

(c)

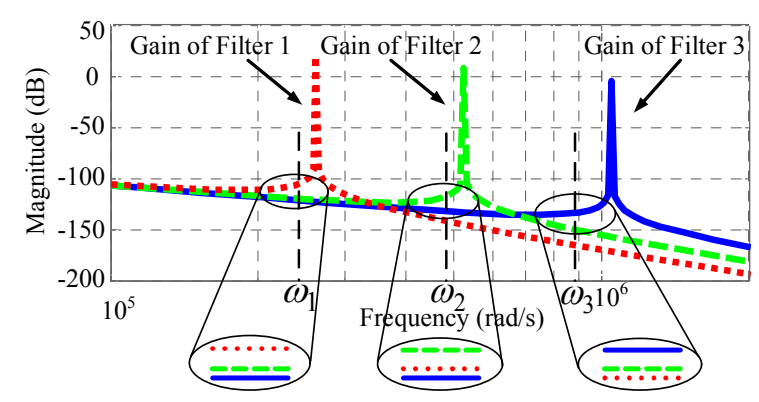

(d)

Fig. 3. Band amplification filter: (a) Circuit diagram; (b) Gain plot of transfer function for a filter; (c) Gain plot of transfer function for two filters; (d) Gain plot of transfer function for three filters. function of the filter is given as (1). The variation in the magnitude of the transfer function with the switching frequency is shown in Fig. 3(b), and it has two peak frequencies, $\omega_{p 1}$ and $\omega_{p 2}$, as expressed by (2) and (3). The magnitude at these frequency is restricted by the ESRs of the capacitors and DCRs of the inductors.

$$
\begin{aligned}
\frac{V_{2 k}}{V_{0 k}} & =\frac{1}{A s^{4}+B s^{2}+1} \\
\left(\because A=L_{0 k} L_{1 k} C_{0 k} C_{2 k}\right. & \left., B=L_{0 k} C_{0 k}+L_{0 k} C_{2 k}+L_{1 k} C_{2 k}\right) \\
\omega_{p 1} & =\sqrt{\frac{B-\sqrt{B^{2}-4 A}}{2 A}} \\
\omega_{p 2} & =\sqrt{\frac{B+\sqrt{B^{2}-4 A}}{2 A}}
\end{aligned}
$$

where the subscript $k$ means the order in the cells. $V_{2 k}$ expresses the voltage applied to the $k^{\text {th }}$ cell and $V_{0 k}$ expresses the voltage of the $k^{\text {th }}$ secondary winding. $L_{l k}$ and $C_{0 k}$ represent the inductance and capacitance of the $k^{\text {th }} \mathrm{CL}$ filter. $L_{0 k}$ and $C_{2 k}$ represent the leakage inductance of the $k^{t h}$ secondary winding and the capacitance of the $k^{\text {th }}$ battery. As the capacitance of the battery cell is much higher than the other values, the first peak frequency is affected only by the cell capacitance and the second peak frequency is affected only by the capacitance of the filter. This property is shown in Fig. 3(c) which represents the transfer functions of the two different filters. These filters have the same parameters except for the capacitor of the filter. The first peak frequencies of both filters are similar because of the same battery capacitance. However, the second peak frequencies are unequal because of their different filter capacitances. According to the capacitance of the filter, each filter reveals a different gain at particular frequencies as shown in Fig. 3(d). Therefore, this implies that the magnitude of the specific filter gain can be higher than that of the other filters at a particular frequency. For example, at the frequency $\omega_{1}$, the gain of Filter 1 is higher than that of others according to the following relationship.

$$
\left|H_{\text {filter } 1}\left(\omega_{1}\right)\right|>\left|H_{\text {filter } 2}\left(\omega_{1}\right)\right|>\left|H_{\text {filter } 3}\left(\omega_{1}\right)\right|
$$

At the frequency $\omega_{3}$, the gain of Filter 3 is higher than that of the others as expressed bellow.

$$
\left|H_{\text {filter } 3}\left(\omega_{3}\right)\right|>\left|H_{\text {filter } 2}\left(\omega_{3}\right)\right|>\left|H_{\text {filter } 1}\left(\omega_{3}\right)\right|
$$

Using this property, the lower secondary voltage in the multi-winding transformer can be controlled. At the proper frequency, the higher gain of the designed filter increases the output voltage applied to the cell. As a result, the nonuniformity in the lower turn-ratio can be reduced.

However, as mentioned above, the non-uniform turnratio can cause lower secondary voltage as well as higher 
secondary voltage. In the case of a higher secondary voltage, the magnitude of the filter gain should be lower than that of the others for voltage difference compensation. However, due to the filter characteristics, no frequency can satisfy this condition with the proposed band amplification CL filter as shown in Fig. 3(d). For example, the gain of Filter 3 in Fig. 3(d) cannot be lower than that of Filter 2 and Filter 1 at the same time. Therefore, other types of filters that can reduce the transfer function gain are required.

\subsection{Band attenuation $\mathrm{LC}$ filter}

For the case of lower turn-ratios, the opposite characteristic of the filter is introduced as shown in Fig. 4(a). A transfer function of this band attenuation LC filter is expressed as (6). This transfer function has three peak frequencies, $\omega_{p 1}, \omega_{p 2}$, and $\omega_{p 3}$ as in (7), (8), and (9).

$$
\begin{gathered}
\frac{V_{2 k}}{V_{0 k}}=\frac{L_{1 k} C_{1 k} s^{2}+1}{A s^{4}+B s^{2}+1} \\
\left(\because A=L_{0 k} L_{1 k} C_{1 k} C_{2 k}, B=L_{1 k} C_{1 k}+L_{1 k} C_{2 k}+L_{0 k} C_{2 k}\right) \\
\omega_{p 1}=\sqrt{\frac{B-\sqrt{B^{2}-4 A}}{2 A}} \\
\omega_{p 2}=\sqrt{\frac{B+\sqrt{B^{2}-4 A}}{2 A}} \\
\omega_{p 3}=\sqrt{\frac{1}{L_{1 k} C_{1 k}}}
\end{gathered}
$$

where $L_{l k}$ and $C_{l k}$ refer to inductance and capacitance of the $k^{\text {th }}$ LC filter. The meaning of the other symbols has already been explained previously. (7) and (8) are second

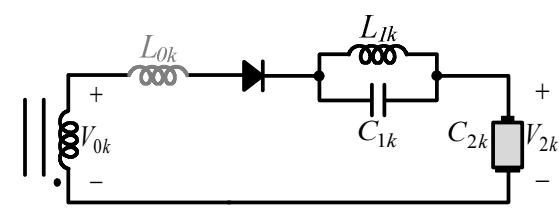

(a)

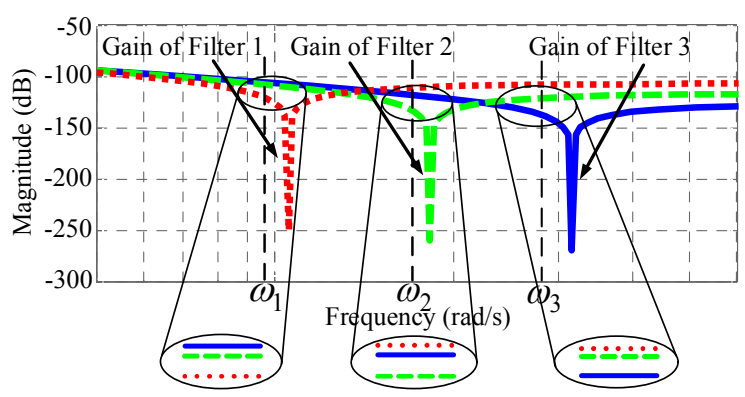

(b)

Fig. 4. Band attenuation filter: (a) Circuit diagram; (b) Gain plot of transfer function. order poles of the transfer function. Therefore, the gain magnitudes at those frequencies show a similar property with the band amplification CL filter. The value of $\omega_{p 3}$ is a second order zero of the transfer function and, consequently, the gain magnitude at this frequency represents an opposite characteristic compared to the other frequencies. With the different values of the filter capacitances, the magnitude of each filter according to the frequency is presented in Fig. 4(b). The gain of a certain filter can be reduced at a particular frequency. For example, the gain of Filter 1 is lower than the others at the frequency, $\omega_{1}$ and the gain of Filter 3 is lower than the others at the frequency $\omega_{3}$. When the voltage at a certain secondary winding is higher than that of others, the voltage difference can be reduced by selecting a proper frequency. However, the filter has a similar problem with the band amplification CL filter; it cannot be applied to the lower secondary voltage case. This is because the magnitude of the particular filter gain cannot be higher than that of the other filter gains at any frequency as shown in Fig. 4(b). For example, the gain of Filter 3 in Fig. 4(b) cannot be higher than that of Filter 2 and Filter 1 at the same time.

\subsection{Generalized CLC Filter}

The two types of filters mentioned above can only be used for specific cases. The band amplification CL filter is used for the lower secondary voltage case and the band attenuation LC filter is used for the higher secondary voltage case. In this paper, a general filter with the characteristics of both these filters is proposed, as shown in Fig. 5(a), to control the secondary voltage in either case. The only difference between these two filters is the position of the filter capacitor. The capacitor of the CL filter is connected in parallel to the series circuit of the

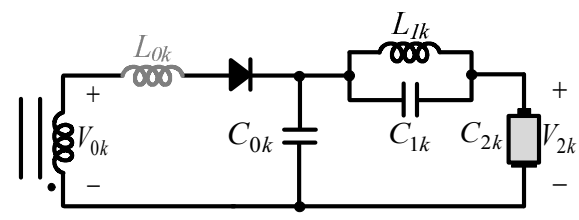

(a)

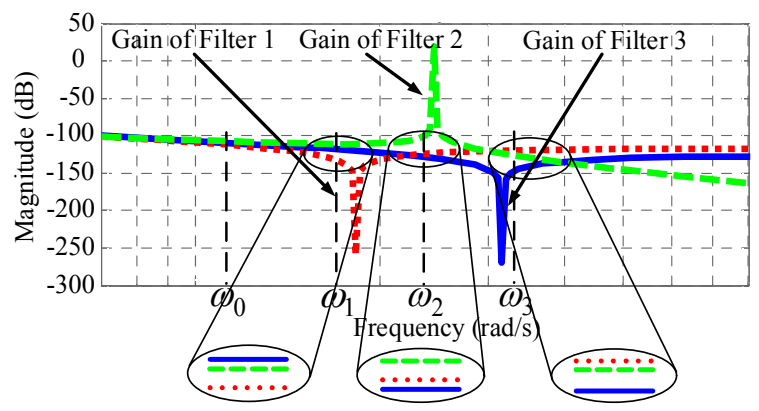

(b)

Fig. 5. Generalized filter: (a) Circuit diagram; (b) Gain plot of transfer function. 
filter inductor and the battery cell. As for the LC filter, the capacitor is connected in parallel to the filter inductor. Therefore they can both be combined to a single structure in the generalized filter of Fig. 5(a). This general filter is used as the band amplification CL filter by removing the $C_{l k}$ for the lower voltage case and as the band attenuation LC filter by removing $C_{0 k}$ for the higher voltage case. For example, the gain plot of the transfer function with three general filters is shown in Fig. 5(b). Two filters are used as $\mathrm{CL}$ filters and the other one is used as an LC filter. As a result, at the frequency $\omega_{2}$, the gain of Filter 2 is higher than that of the others as follows.

$$
\left|H_{\text {filter } 2}\left(\omega_{2}\right)\right|>\left|H_{\text {filter } 1}\left(\omega_{2}\right)\right|>\left|H_{\text {filter } 3}\left(\omega_{2}\right)\right|
$$

At the frequency $\omega_{3}$, the gain of Filter 3 is lower than that of others as follows.

$$
\left|H_{\text {filter } 3}\left(\omega_{3}\right)\right|<\left|H_{\text {filter } 2}\left(\omega_{3}\right)\right|<\left|H_{\text {filter } 1}\left(\omega_{3}\right)\right|
$$

\subsection{Cell Selection}

The gain of each filter is changed according to the switching frequency, as shown in Fig. 5(b). Using these characteristics, it is possible to select a particular cell for an individual control. In other words, the proposed method can choose a specific cell by means of switching frequency selection. As the number of cells increases, the number of adjusted switching frequencies and the required filters for cell selection also increases. As a result, the range of the required switching frequency becomes wider. The wide range of the switching frequency can adversely affect the transformer core design. To reduce this negative effect, the proposed method can work not for all cells but for the cell with the winding which has the worst non-uniform turnratio. In addition, by grouping several windings that have similar properties, the number of the adjusted switching frequencies can be reduced.

\section{Control Method and Filter Design}

\subsection{Filter design}

The non-uniform turn-ratios are caused by the manufacturing deviation of the transformer. The proposed filter therefore needs to be designed for the corresponding transformer. First, the output voltage at each secondary side winding is measured to check the non-uniform turnratio. To execute this step, the primary side of the flyback converter is connected to the voltage source and the secondary side is not connected to anything, which means an open circuit. Then, the type of filter is determined according to the type of non-uniform turn-ratio. If the voltage of a certain secondary winding is higher than the average voltage, the general filter is used as a CL filter. For the opposite case, the general filter is used as an LC filter. The capacitance, inductance, and peak frequency of the filter are determined as follows.

In the band amplification CL filter, the switching frequency can be determined from (3). Due to the much larger value of $C_{2 k}$, the peak frequency (3) can be approximated as follows.

$$
\omega_{p 2} \approx \sqrt{\frac{L_{0 k}+L_{1 k}}{L_{0 k} L_{1 k} C_{0 k}}}
$$

In case of the band attenuation LC filter, the switching frequency can be determined from (13) which is one of the three peak frequencies. In a prototype circuit, a $10 \mu \mathrm{H}$ inductor and a capacitor with micro capacitance are used.

$$
\omega_{p 3}=\sqrt{\frac{1}{L_{1 k} C_{1 k}}}
$$

\subsection{Proposed control method}

The control algorithm for the proposed method is similar to the conventional one which is simplistic because of a single switch. In the case of an unbalanced cell, it only needs to start switching at a certain frequency. However, the proposed method should consider the specific cells affected by the non-uniform turn-ratios. First, the voltage of each cell is sensed continuously to enable the detection of the unbalanced cell. When the unbalance is detected, the corresponding cells are distinguished to determine the switching frequency. If the unbalanced cell is connected to the Filter 1, the cell balancing procedure is performed at switching frequency $f_{s w l}$.

The proposed method requires one more consideration. The filter can control only the transient state of the balancing procedure because different gain magnitudes of the filter do not imply anything more than a different charging speed. In other words, the proposed filter has no effects in the steady state. Therefore, if the switching for the balancing is continued until the steady state, cell voltages become unbalanced again regardless of the proposed filter. To prevent this problem, a balancing on-off control method is introduced. The balancing process is ceased in the range near the average cell voltage. The entire sequence of the control method is represented in the form of a flowchart in Fig. 6. For example, assume that the cell balancing including three filters in Fig. 5(b) is performed. When the voltage of a certain cell is lower than the average by the threshold value, the balancing process is initiated as follows. If the cell is connected to a nonadjusted filter, the balancing starts at a frequency of $\omega_{0}$ as shown in Fig. 5(b). The gain values of the three filters are the same at this frequency. If the cell is connected to Filter 2 , the balancing begins at a selected frequency of $\omega_{2}$ for the 


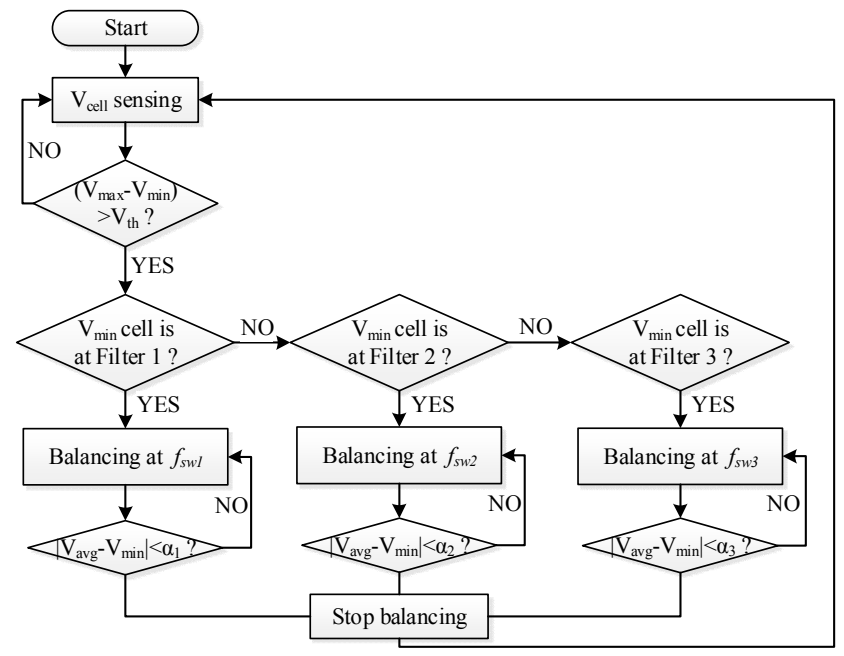

Fig. 6 The flowchart of the control algorithm with the proposed on-off control.

higher gain than the other filters. The balancing is ceased when the difference between the average cell voltage and the voltage of the unbalanced cell is lower than a certain value.

\section{Simulation and Experimental Results}

To illustrate the dynamic property of the proposed method, the balancing operation for the 4 super-capacitor module is simulated. Fig. 7 shows the simulation model of the proposed circuit. The turn-ratios of the windings that are connected to Cell 1 and Cell 2 are intentionally adjusted to assume the non-uniform turn-ratio. Filter 1 is set as the band attenuation filter and Filter 2 is set as the band amplification filter. Other filters are designed to be unaffected by the adjusted switching frequencies of Filter 1 and Filter 2. There are two unbalanced cells in each simulation case. One of them is the comparison cell connected to the normal winding and the other is the target

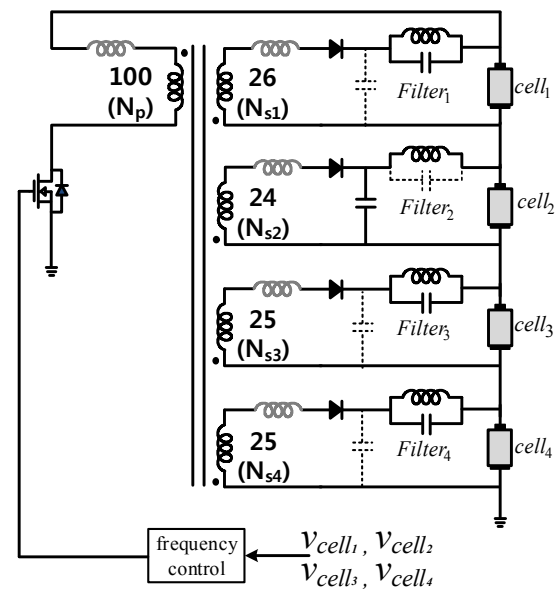

Fig. 7. Simulation model of proposed circuit. cell connected to the adjusted winding. As shown in Fig. 7, the cell balancing is controlled by the switching frequency control while the switching duty is kept fixed.

In the first case, the winding of the adjusted filter has a lower turn-ratio than that of the others, implying that the voltage at the secondary winding is lower than at the other windings. Moreover, without the proposed method, the voltage of the target cell is lower than that of the comparison cell as shown in Fig. 8(a). However, by using the adjusted filter and the proper frequency, which increases the gain of the adjusted filter, the charging speed of the target cell is increased. Consequently, the gap between the comparison cell and the target cell is reduced as shown in Fig. 8(b). In contrast, the opposite case of the simulation is performed and plotted in Fig. 9. The windings of the controlled filter have a higher turn-ratio than the others. As shown in Fig. 9(a), there is steady state error due to the higher voltage of the secondary winding. With the adjusted filter and the proper frequency, which reduces the magnitude of the gain, the balancing current of the target cell is reduced. As a result, the gap between the comparison cell and the target cell is reduced as shown in Fig. 9(b).

To show the feasibility of the proposed method, a cell balancing of eight Li-Po batteries is executed using a single switch flyback converter with multi-winding transformer and adjusted filters. The turn-ratios of the adjusted windings are designed in two ways. The first one reveals higher turn-ratios case, while the second one represents a lower turn-ratios case. Other parameters of the prototype

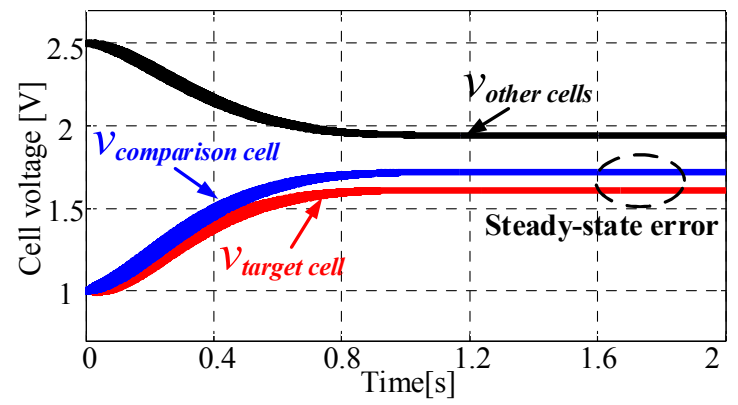

(a)

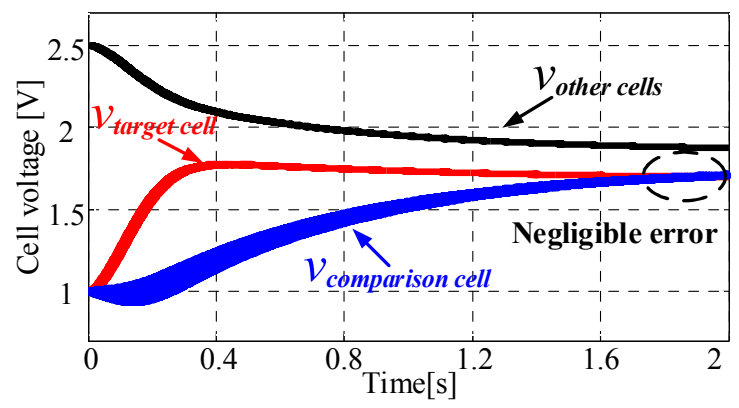

(b)

Fig. 8. Cell voltages in the cell balancing with low secondary voltage at target cell: (a) The conventional method; (b) The proposed method. 


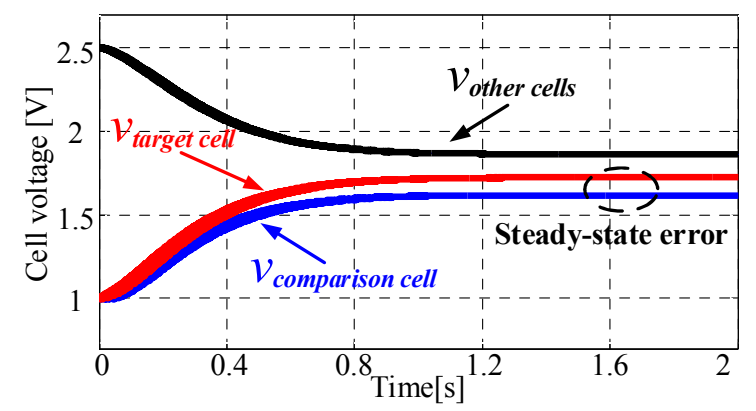

(a)

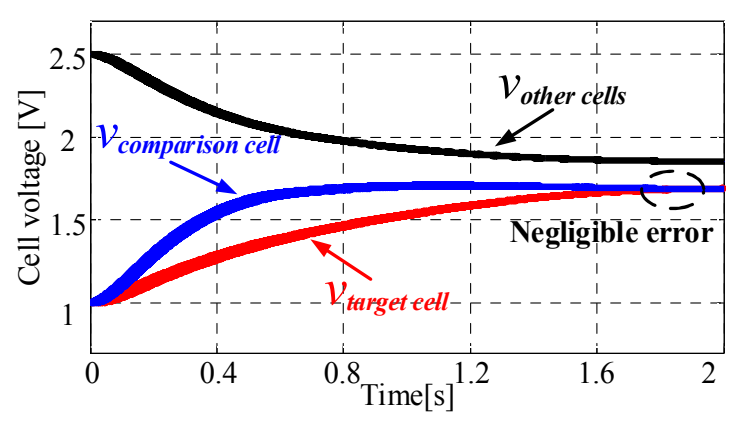

(b)

Fig. 9. Cell voltages in the cell balancing with high secondary voltage at target cell: (a) The conventional method; (b) The proposed method.

Table 1. Parameters of the prototype circuit.

\begin{tabular}{c|c|c}
\hline & $\begin{array}{c}\text { Low secondary } \\
\text { voltage }\end{array}$ & $\begin{array}{c}\text { High secondary } \\
\text { voltage }\end{array}$ \\
\hline Turn ratio of target cell & $40: 4.7$ & $40: 5.4$ \\
\hline Turn ratio of others & $40: 5$ & $40: 5$ \\
\hline Switching frequency & $24.4 \mathrm{kHz}$ & $32 \mathrm{kHz}$ \\
\hline $\begin{array}{c}\text { Filter parameters of the } \\
\text { target cells }\end{array}$ & $\begin{array}{c}\mathrm{L} 1=10 \mu \mathrm{H}, \mathrm{C} 0=9.4 \mu \mathrm{F} \\
\mathrm{C} 1=0\end{array}$ & $\begin{array}{c}\mathrm{L} 1=10 \mu \mathrm{H}, \mathrm{C} 0=0 \\
\mathrm{C} 1=2 \mu \mathrm{F}\end{array}$ \\
\hline $\begin{array}{c}\text { Filter parameters of the } \\
\text { comparison cells }\end{array}$ & $\begin{array}{c}\mathrm{L} 1=10 \mu \mathrm{H}, \mathrm{C} 0=4.7 \mu \mathrm{F} \\
\mathrm{C} 1=0\end{array}$ & $\mathrm{~L} 1=10 \mu \mathrm{H}, \mathrm{C} 0=4.7 \mu \mathrm{F}$ \\
$\mathrm{C} 1=0$
\end{tabular}

Table 2. Parameters of the battery module

\begin{tabular}{c|c}
\hline \multicolumn{2}{|c}{ Lithium-polymer battery } \\
\hline Number of cells & 8 \\
\hline Capacity & $1000 \mathrm{mAh}$ \\
\hline Initial voltage of target cell & $2.9 \mathrm{~V}$ \\
\hline Initial voltage of comparison cell & $2.9 \mathrm{~V}$ \\
\hline Initial voltage of other cells & $3.6 \mathrm{~V}$ \\
\hline
\end{tabular}

circuit are summarized in Table 1 and the parameters of the battery module are described in Table 2 . First, the dynamic performance of the proposed filter is exhibited in Fig. 10. In the conventional method, since the voltages of the two cells are the same at the initial state, the balancing currents remain the same for both cells, regardless of the switching frequency. However, in the proposed method, the change of the switching frequency causes the balancing currents to vary. As shown in Fig. 10, the balancing current is far from an ordinary waveform because of the adjusted filter

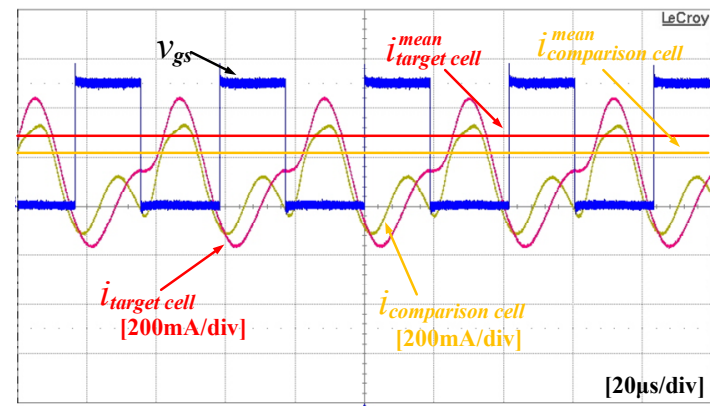

(a)

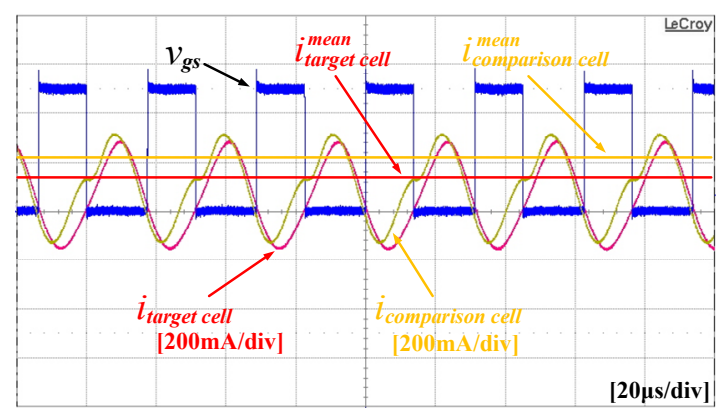

(b)

Fig. 10. The current of the target and comparison cell in the cell balancing: (a) At switching frequency of 24.4 $\mathrm{kHz}$; (b) At switching frequency of $32 \mathrm{kHz}$.

and switching frequency. However, average value of these currents represents different values according to the switching frequency. These switching frequencies can be obtained from the peak frequency of each filter. At the switching frequency of $24.4 \mathrm{kHz}$, the average balancing current of the target cell is higher than that of the comparison cell as shown in Fig. 10(a). The switching frequency of $32 \mathrm{kHz}$, the average balancing current of the target cell is lower than that of the comparison cell as shown in Fig. 10(b). These switching frequencies are quite low for the flyback converter topology. Because of digital implementation, available switching frequency is restricted in this paper. But it is possible to use higher frequencies if they are available. Using this property, the two cases of experiments were performed.

In the case of a low secondary voltage, the target cell is connected to the lower turn-ratio winding and the comparison cell is connected to the normal winding. At the normal switching frequency, the voltage of the target cell is lower than that of the comparison cell as shown in Fig 11(a). At the switching frequency selected for the band amplification, the voltage difference is reduced by $55 \%$ as shown in Fig. 11(b). In contrast, Fig. 12 shows the cell voltages in the cell balancing procedure when the target cell is connected to the higher turn-ratio, winding and the comparison cell is connected to the normal winding. As shown in Fig. 12(a) the voltage of the target cell is higher than that of the comparison cell at normal switching frequency. However, at the switching frequency selected 


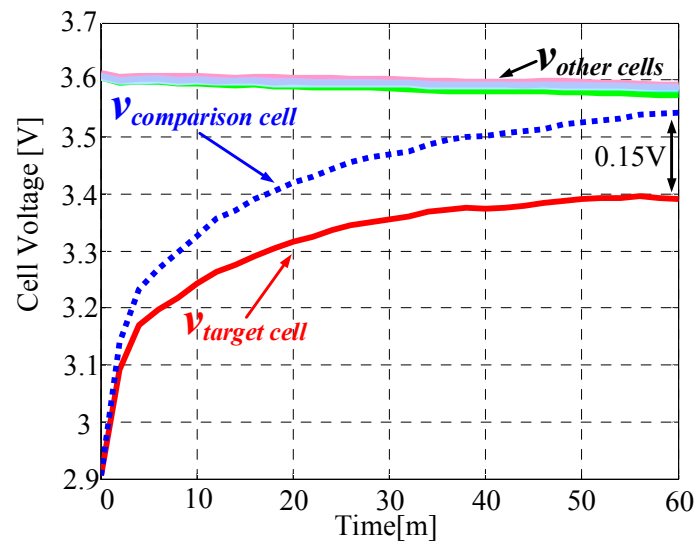

(a)

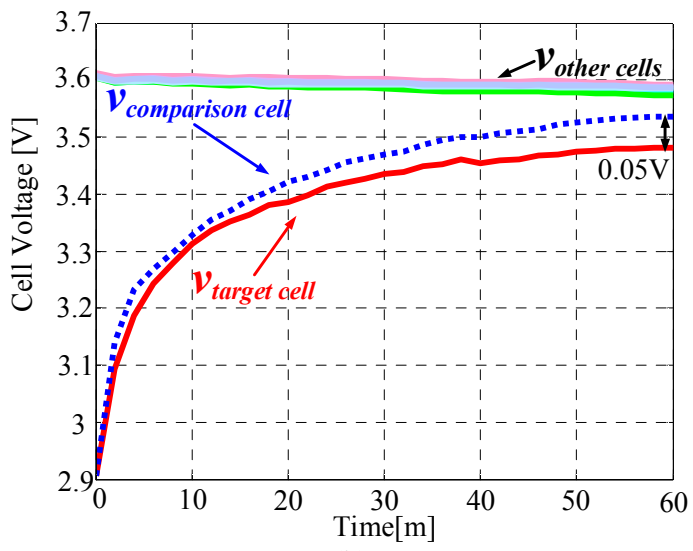

(b)

Fig. 11. Cell balancing voltages with low secondary voltage in the target cell: (a) At the normal switching frequency; (b) At the selected switching frequency.

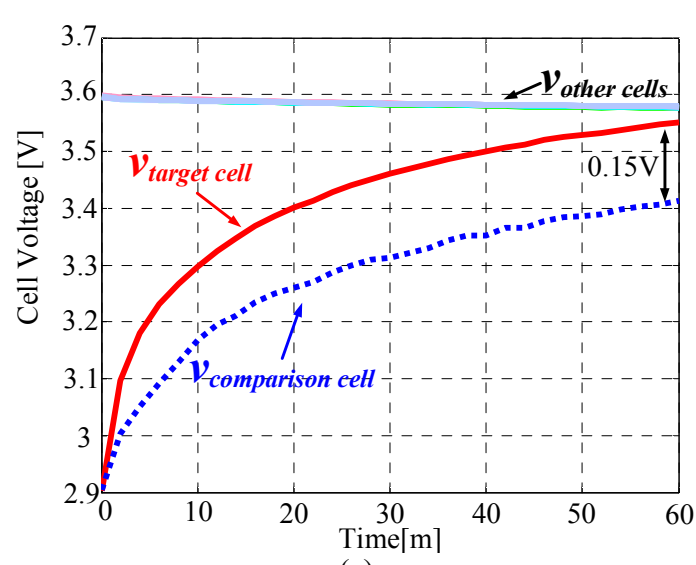

(a)

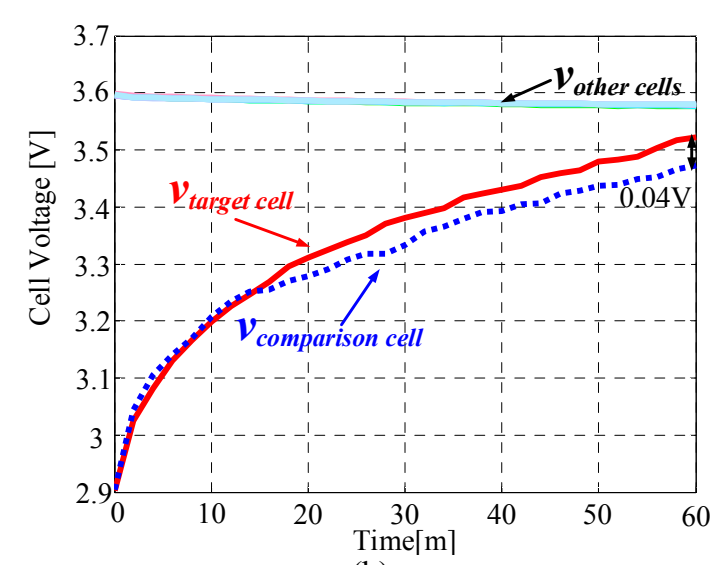

(b)

Fig. 12. Cell balancing voltages with high secondary voltage in the target cell: (a) At the normal switching frequency; (b) At the selected switching frequency.

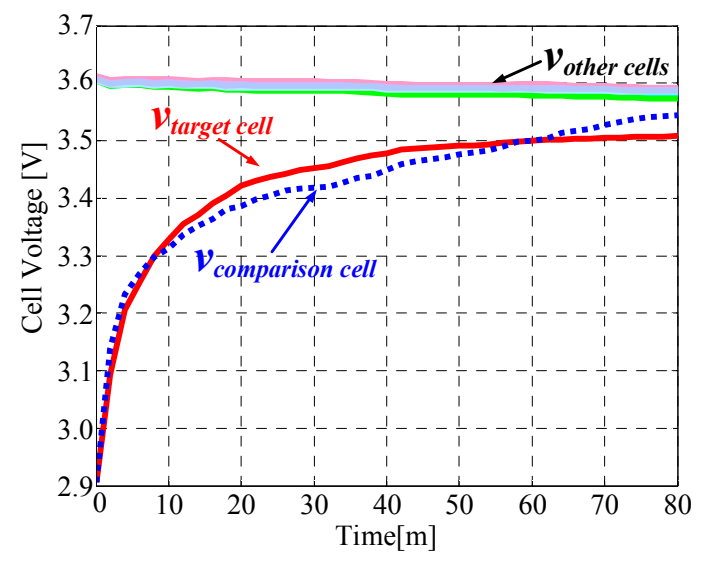

(a)

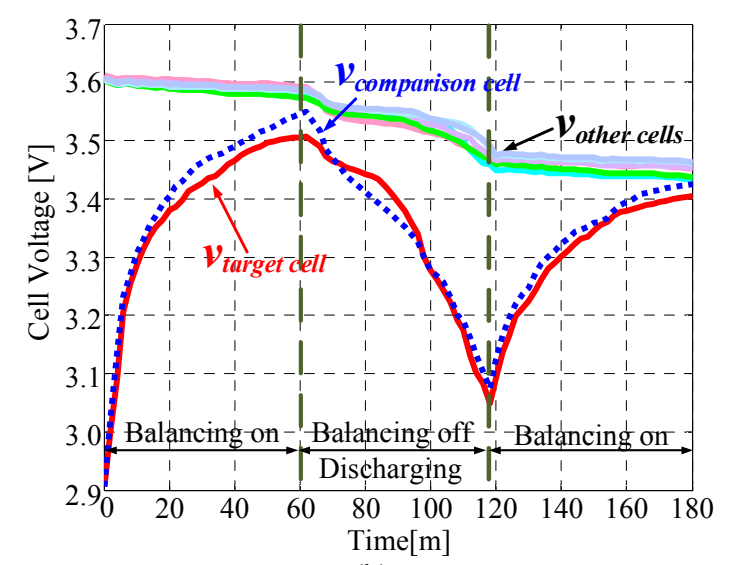

(b)

Fig. 13. Cell voltages in the long term cell balancing: (a) Without the on-off control; (b) With the on-off control.

for the band attenuation, the difference in the cell voltage is reduced by $60 \%$ as shown in Fig. 12 (b).

As explained earlier in Section 3, the balancing process is ceased when the voltage difference is lower than a certain value. To show the dynamic performance, a long term cell balancing control is executed and the result of the conventional method and the proposed method are compared. Experimental conditions remain the same as in 
the lower secondary voltage case. Without the proposed method, the balancing voltages of the two cells in Fig. 13(a) would be different just like it is presented in Fig. 11(a). However, because of the proposed filter and the adjusted switching frequency, the balancing voltages of the two cells become similar until 60 minutes. After that, the proposed filter becomes ineffective. As shown in Fig. 13(a), the voltage gap again widens. This weakness can be compensated for by the proposed on-off control as shown in Fig. 13(b). The balancing process is off when the voltage difference is lower than a certain value. If there is an unbalance that occurs again after the discharging or charging sequence, the balancing process can be repeated as shown in Fig. 13(b).

\section{Conclusion}

This paper proposed a cell balancing method using generalized filters and a single switch flyback converter with multi-winding transformer. A general LC or CL filter is used in each secondary winding, which is adjusted as a band amplification or attenuation type. Each cell can be controlled individually by the frequency selection because each designed filter has a difference in the capacitance. The differences in the non-uniform turn-ratios in a multiwinding transformer are compensated by the proposed filter design and the switching frequency selection. In considering the characteristic of the filter which can only change transient state, the on-off control method of the switching process is also proposed. Ultimately, the comparative experimental results with eight Li-Po cells confirmed that the proposed method reduces the voltage difference in the target cells without any cell selection switches.

\section{Acknowledgements}

This work was supported by the Robot industry fusion core technology development project of the Ministry of Trade, Industry \& Energy of KOREA(10052980) and the Brain Korea 21 Plus Project in 2015.

\section{References}

[1] L. Shuai, K. A. Corzine, and M. Ferdowsi, "A new battery/ultracapacitor energy storage system design and its motor drive integration for hybrid electric vehicles," IEEE Trans. Veh. Technol., vol. 56, no. 4, pp. 1516-1523, Jul. 2007.

[2] I. Aharon and A. Kuperman, "Topological overview of power trains of battery powered vehicles with range extenders," IEEE Trans. Power Electron., vol. 26, no. 3, pp. 868-876, Mar. 2011.
[3] P. A. Cassani and S. S. Williamson, "Design, Testing, and Validation of a Simplified Control Scheme for a Novel Plug-In Hybrid Electric Vehicle Battery Cell Equalizer," IEEE Trans. Industrial Electronics, vol. 57, no. 12, pp. 3956-3962, Dec. 2010

[4] F. Altaf, L. Johannesson and B. Edgardt, "On thermal and state-of-charge balancing using cascade multilevel converters," Journal of Power Electronics, Vol. 13, No. 4, pp. 569-583, Jul. 2013.

[5] S. J. Huang, F. S. Pai, and B. G. Huang. "A matching design for ultra-capacitor and Li-ion battery cooperation in electric wheel motors." IEEE SICE Annual Conf., Aug 2010, pp. 2646-2649.

[6] L. Y. Wang, P. Michael, G. G. Yin, W. Chen, Y. Fu, C. C. Mi, "Battery Cell Identification and SOC Estimation Using String Terminal Voltage Measurements," IEEE Trans. Vehicular Technology, vol. 61, no. 7, pp. 2925-2935, Sept. 2012

[7] Y. Zhao, H. Yun, S. Liu, H. Jiao, C. Wang, "State-ofcharge Estimation for Lithium-ion Batteries Using a Multi-state Closed-loop Observer," Journal of Power Electronics, Vol. 14, No. 5, pp. 1038-1046, May 2015.

[8] C. Fleischer, W. Wagg, Z. Bai and D. U. Sauer, "Adaptive On-line State-of available-power prediction of lithium-ion batteries," Journal of Power Electronics, Vol. 13, No. 4, pp. 516-527, Jul. 2013.

[9] W.C. Lee, D. Drury and P. Mellor, "Comparison of Passive Cell Balancing and Active Cell Balancing for Automotive Batteries," IEEE Vehicle Power Propulsion Conf., Sep. 2011, pp.1-7

[10] W. C. Lee, D. Drury, "Development of a Hardwarein-the-Loop Simulation System for Testing Cell Balancing Circuits," IEEE Trans. Power Electronics, vol.28, no.12, pp.5949-5959, Dec. 2013

[11] A. Affanni, A. Bellini, G. Franceschini, P. Guglielmi, and C. Tassoni, "Battery choice and management for new-generation electric vehicles," IEEE Trans. Ind. Electron., vol. 52, no. 5, pp. 1343-1349, Oct. 2005.

[12] A. M. Imtiaz, and F. H. Khan. "Time Shared Flyback Converter" Based Regenerative Cell Balancing Technique for Series Connected Li-Ion Battery Strings.”, IEEE Trans. Power Electron., vol. 28, no. 12, pp. 5960-5975, Dec. 2013.

[13] W. Wang, F. Wu, K. Zhao, L. Sun, J. Duan, D. Sun, "Elimination of the State-of-Charge Errors for Distributed Battery Energy Storage Devices in Islanded Droop-controlled Microgrids," Journal of Power Electronics, Vol. 15, No. 4, pp. 1105-1118, Apr. 2015.

[14] B. T. Kuhn, G. E. Pitel, and P. T. Krein, "Electrical properties and equalization of lithium-ion cells in automotive applications," in Proc. IEEE Vehicle Power Propulsion Conf., 2005, pp. 55-59.

[15] C. Pascual and P. T. Krein, "Switched capacitor system for automatic series battery equalization," in Proc. IEEE Appl. Power Electron. Conf. Exp., 1997, pp. $848-854$. 
[16] S. G. Song, S. M. Park, S. J. Park, "New Battery Balancing Circuit using Magnetic Flux Sharing," Journal of Power Electronics, Vol. 14, No. 1, pp. 194201, Jan. 2015.

[17] J. Sun, C. Zhu, R. Lu, K. Song, G. Wei, “Development of an Optimized Algorithm for Bidirectional Equalization in Lithium-Ion Batteries," Journal of Power Electronics, Vol. 15, No. 3, pp. 775-785, Mar. 2015.

[18] A. M. Imtiaz, F. H. Khan, "Time Shared Flyback Converter Based Regenerative Cell Balancing Technique for Series Connected Li-Ion Battery Strings," IEEE Trans. Power Electronics, vol. 28, no. 12, pp. 5960-5975, Dec. 2013

[19] Y. Yuanmao, K. W. E. Cheng, and Y. P. B. Yeung, "Zero - current switching switched - capacitor zerovoltage-gap automatic equalization system for series battery string," IEEE Trans. Power Electron., vol. 27, no. 7, pp. 3234-3242, Jul. 2012

[20] M. Kultgen and J. Munson, "Battery stack monitor extends life of Li-on batteries in hybrid electric vehicles," Linear Technol. Mag., vol. 19, pp. 1-8, Mar. 2009.

[21] B. Lindemark, "Individual cell voltage equalizers (ICE) for reliable battery performance," in Proc. IEEE Int. Telecommun. Energy Conf., 1991, pp. 196201.

[22] M. Einhorn, W. Roessler, and J. Fleig, "Improved performance of serially connected Li-ion batteries with active cell balancing in electric vehicles," IEEE Trans. Veh. Technol., vol. 60, no. 6, pp. 2448-2457, Jul. 2011.

[23] J. C. Wu, H.L. Jou, J. H. Tsai, “A Buck-Boost Type Charger with a Switched Capacitor Circuit", Journal of Power Electronics, Vol. 15, No. 1, pp. 31-38, Jan. 2015.

[24] A. C. Baughman and M. Ferdowsi, "Double-tiered switched-capacitor battery charge equalization technique," IEEE Trans. Ind. Electron., vol. 55, no. 6, pp. 2277-2285, Jun. 2008

[25] N. H. Kutkut, H. L. N. Wiegman, D. M. Divan, and D. W. Novotny, "Design considerations for charge equalization of an electric vehicle battery system," IEEE Trans. Ind. Appl., vol. 35, no. 1, pp. 28-35, Feb. 1999.

[26] W. Hu, F. Zhang, Y. Xu, X. Chen, “Output Voltage Ripple Analysis and Design Considerations of Intrinsic Safety Flyback Converter Based on Energy Transmission Modes," Journal of Power Electronics, Vol. 14, No. 5, pp. 908-917, May 2015.

[27] N. H. Kutkut, D. M. Divan and D. W. Novotny, "Charge equalization of series connected battery strings," IEEE Trans. Industry Applications, vol. 31, no. 3, pp. 562-568, May 1995.

[28] X. Wei, X. Zhao, and D. Haifeng, "The application of flyback DC/DC converter in Li-ion batteries active balancing," in Proc. IEEE Vehicle Power Propulsion Conf., Sep. 7-10, 2009, pp. 1654-1656.

[29] J. W. Shin, G. S. Seo, C. Y. Chun, and B. H. Cho, "Selective Flyback Balancing Circuit with Improved Balancing Speed for Series Connected Lithium-ion Batteries," International Power Electronics Conf, pp. 1180-1184, August 2010.

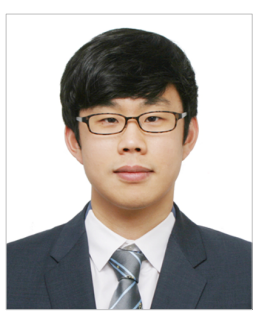

Jin-Woong Kim (S'12) was born in Korea in 1986. He received the B.S. degree in electrical engineering in 2012 from Seoul National University, Seoul, Korea, where he is currently working toward the Ph.D. degree. His current research interests include renewable energy conversion system and battery management system.

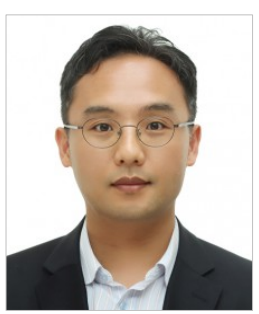

Jung-Ik Ha (S'97-M'01-SM'12) was born in Korea in 1971. He received the B.S., M.S., and Ph.D. degrees in electrical engineering from Seoul National University, Seoul, Korea, in 1995, 1997, and 2001, respectively. From 2001 to 2002, he was a Researcher in Yaskawa Electric Co., Japan. From 2003 to 2008 , he was with Samsung Electronics Co., Korea, as a Senior and Principal Engineer. From 2009 to 2010, he was the Chief Technology Officer at LS Mechapion Co., Korea. Since 2010, he has been with the Department of Electrical and Computer Engineering, Seoul National University, where he is currently an Associate Professor. His current research interests include circuits and control in high efficiency and integrated electric energy conversions for various industrial fields. 